\title{
Using student interviews for becoming a reflective geographer
}

Adriansen, Hanne Kirstine Olesen; Madsen, Lene Møller

Published in:

Journal of Geography in Higher Education

DOI:

10.1080/03098265.2014.936310

Publication date:

2014

Document version

Early version, also known as pre-print

Citation for published version (APA):

Adriansen, H. K. O., \& Madsen, L. M. (2014). Using student interviews for becoming a reflective geographer. Journal of Geography in Higher Education, 38(4), 595-605. [Selected for publication as Chapter 5 in Haigh, M., Cotton, D. and Hall, T. (eds.) (2016): Pedagogic Research in Geography Higher Education, Routledge.]. https://doi.org/10.1080/03098265.2014.936310 
This article was downloaded by: [Copenhagen University Library]

On: 14 August 2014, At: 08:36

Publisher: Routledge

Informa Ltd Registered in England and Wales Registered Number: 1072954 Registered

office: Mortimer House, 37-41 Mortimer Street, London W1T 3J H, UK

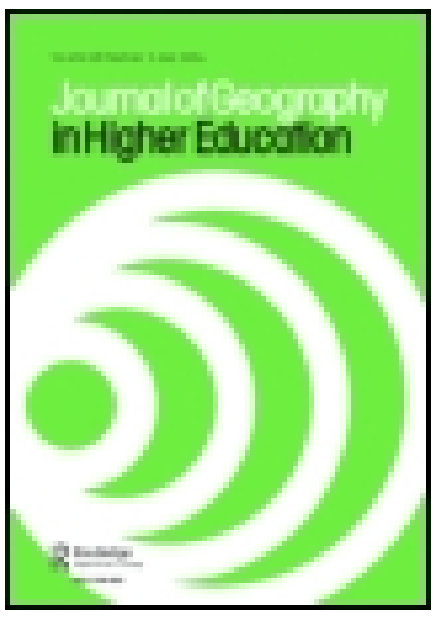

\title{
J ournal of Geography in Higher Education
}

Publication details, including instructions for authors and subscription information:

http:// www.tandfonline.com/loi/ cjgh20

\section{Using student interviews for becoming a reflective geographer}

\author{
Hanne Kirstine Adriansen ${ }^{a} \&$ Lene Møller Madsen ${ }^{b}$ \\ a Department of Education, Aarhus University, Tuborgvej 164, \\ 2400, Copenhagen N, Denmark \\ ${ }^{b}$ Department of Science Education, University of Copenhagen, \\ Øster Voldgade 3, 1350, Copenhagen K, Denmark \\ Published online: $15 \mathrm{~J}$ ul 2014.
}

To cite this article: Hanne Kirstine Adriansen \& Lene Møller Madsen (2014): Using student interviews for becoming a reflective geographer, J ournal of Geography in Higher Education, DOI: 10.1080/ 03098265.2014.936310

To link to this article: http:// dx.doi.org/ 10.1080/ 03098265.2014.936310

\section{PLEASE SCROLL DOWN FOR ARTICLE}

Taylor \& Francis makes every effort to ensure the accuracy of all the information (the "Content") contained in the publications on our platform. However, Taylor \& Francis, our agents, and our licensors make no representations or warranties whatsoever as to the accuracy, completeness, or suitability for any purpose of the Content. Any opinions and views expressed in this publication are the opinions and views of the authors, and are not the views of or endorsed by Taylor \& Francis. The accuracy of the Content should not be relied upon and should be independently verified with primary sources of information. Taylor and Francis shall not be liable for any losses, actions, claims, proceedings, demands, costs, expenses, damages, and other liabilities whatsoever or howsoever caused arising directly or indirectly in connection with, in relation to or arising out of the use of the Content.

This article may be used for research, teaching, and private study purposes. Any substantial or systematic reproduction, redistribution, reselling, loan, sub-licensing, systematic supply, or distribution in any form to anyone is expressly forbidden. Terms \& Conditions of access and use can be found at http://www.tandfonline.com/page/termsand-conditions 


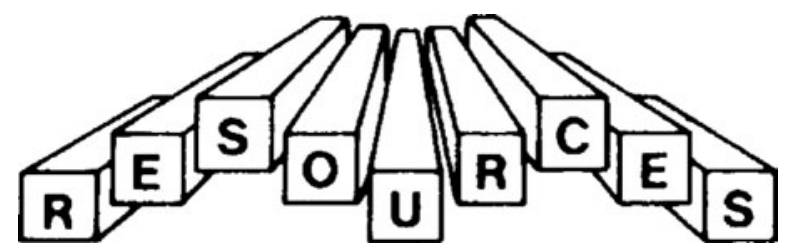

\title{
Using student interviews for becoming a reflective geographer
}

\author{
Hanne Kirstine Adriansen ${ }^{\mathrm{a} *}$ and Lene Møller Madsen ${ }^{\mathrm{b}}$ \\ ${ }^{a}$ Department of Education, Aarhus University, Tuborgvej 164, 2400 Copenhagen N, Denmark; \\ ${ }^{b}$ Department of Science Education, University of Copenhagen, Øster Voldgade 3, 1350 Copenhagen \\ $K$, Denmark
}

(Received 5 July 2013; final version received 26 April 2014)

\begin{abstract}
This paper presents a case for interviewing students as an effective yet complex way to integrate reflexive practice into teaching and research. Even though many human geographers are accustomed to conducting qualitative interviews in various contexts, it is not straightforward to interview one's own students. This paper addresses three issues: implications of doing insider interviews; ethical issues of interviewing students where power relations are at stake and using visual co-constructions as a means of levelling the analytical power of the insider interviewer. We show how student interviews have enhanced our reflection-on-action and give recommendations for prospect student interviewers.
\end{abstract}

Keywords: insider interviews; ethics; analytical power; visual co-constructions; positionality

\section{Introduction}

In this paper, we examine how student interviews can be employed as a means to become reflective geography scholars in relation to our teaching obligations. It deals with both the opportunities that interviewing students open, as well as some of its key challenges. We are inspired by the idea of the reflective practitioner (Schön, 1983). While the concepts and ideas underlying reflective practice date back to researchers such as Dewey (1933) and Piaget, Ackermann, and Berthoud-Papandropoulou (1977), it was Donald Schön's seminal book from 1983 The Reflective Practitioner that brought attention to the idea that professionals, such as teachers, should develop a reflective practice. According to Schön, professionals can become better at their job by developing reflection-in-action and reflection-on-action. The former refers to the ability to reflect on challenges in the situation where and when they unfold, whereas the latter involves systematic reflection after the situation, e.g. teaching a class. Schön has also been of inspiration to geographers: In an edited volume by Ashley Kent directed at teachers of geography at secondary/high school level, the editor writes that the book "attempts [...] above all to encourage reflection by experienced practitioners" (Kent, 2000, p. vii).

*Corresponding author. Email: hkoa@dpu.dk 


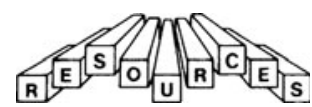

The question is how we can develop this reflective practice? In this paper, we will show how a method that is well known to many human geographers, namely qualitative interviews, can be used in a manner that is unusual to many geographers, namely by interviewing one's own students. Qualitative interviews can provide in-depth understanding of the interviewee's life world (Kvale, 1996); hence by interviewing one's own students, we may gain valuable knowledge about the "how" and "why" of students' learning thereby adding to our reflection-on-action as geographer teachers. Unfortunately, interviewing (one's own) students is not as straightforward as it may seem. At least we were surprised when we began using our extensive interview experience inside academia (Madsen \& Adriansen, 2006; Madsen \& Winslow, 2009). Based on these surprises, we will address three main themes: the implications of doing insider interviews; ethical issues when interviewing one's own students and using visual co-constructions as a means of interviewing. A visual co-construction is an artefact, a paper on which the interview is written and drawn by the interviewer and interviewee. The three themes are interrelated in so far as insider interviews raise special ethical concerns, especially when interviewing one's own students where power relations are at stake, and the creation of visual coconstructions during interviewing can be a means of levelling the analytical power of the interviewer.

The paper offers close reflection on subtle nuances of the interview experience. It gives voice to the concerns that qualitative researchers may have when they interview their own students as a means of getting feedback on teaching and reflecting-on-action. It is based on our own experiences of creating reflection-on-action through student interviews as seen in Example 1 below. With ever increasing demands on productivity and measurable outputs in Academia, it may be difficult to find time for developing a reflective practice. We have found time by combining our reflection on teaching with research, which means we have used our teaching as empirical material for research (e.g. Adriansen, 2010; Adriansen \& Knudsen, 2013). Furthermore, we find developing a reflective teaching practice a more productive way to work towards better teaching than the ranking of teaching and "competition fetish" introduced by management (Naidoo, 2008).

Example 1: Some years ago, we made research interviews with students about their engagement in undergraduate course in Geographical Information Systems (GIS) (Madsen, Christiansen, \& Rump, 2014). These interviews let us to insights about the importance of students' motivations and reasons for choosing a particular course. These interviews showed us in a very direct way how the students' approaches to a learning activity are related to their reasons for attending the course. For example, two students attending the same course in GIS had quite different perspectives: one was almost finished with his studies and wanted to be updated on GIS to get a job within the GIS environment while the other student wanted to learn GIS in order to use it in an assignment in another course to specialise within a certain geography topic. These two students engaged very differently with the learning activities and had different views on the learning objectives of the course. As teachers, we can use this knowledge in other courses to be aware of the importance of going into dialogue with the students about their motivations and intentions with the course, especially if we feel that there is a lack of motivation. By doing so, we create a possibility for ourselves to understand the relevance and perception of the learning activities we try to get the students engaged in.

\section{Insider interviews: interviewing one's own students}

"What do you want to ask me about?" is a common reaction when a researcher/teacher asks students to become interviewees. The question can occur in any potential interview situation, but when the interviewee is a student, there are extra layers to the question. "Is this some type of exam?", "Are there wrong/stupid answers which will haunt me 


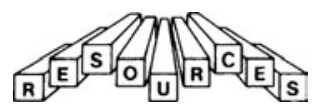

afterwards?", "I like you as a person, but wasn't too impressed with your way of teaching, how can I tell you that?" Likewise the teacher/researcher ${ }^{1}$ may be (and should be) concerned about the ethics involved in interviewing students. Also it can be challenging for the researcher to let students experience the researcher's capabilities as an interviewer. What is at stake here is positionality. The concept positionality refers to the multiple positions the interviewer and the interviewee have and can take on in relation to each other during an interview, such as gender, age, social position, ethnicity and profession. As noted by Chacko: "Positionality is a critical factor in framing social and professional relationships in the field; it sets the tone of the research, affecting its course and its outcomes" (Chacko, 2004, p. 52). A teacher-student interview may have different dynamics than a researcher-informant interview. The different positions of teacher and student will give raise to different power relations and legitimate ways of talking and behaving during an interview. Positions and power can be negotiated throughout the interview - often in subtle ways (Adriansen \& Madsen, 2009).

The issue of positionality has been analysed widely among geographers (Chacko, 2004; DeVerteuil, 2004; McCleery, 2004). This discussion has especially been presented by feminist and post-colonial geographers (e.g. England, 1994; Larner, 1995; Rose, 1997). When interviewing one's own students, it is especially the insider/outsider and in-between position which demands attention. As pointed out by Kitchin and Tate, being an insider may make research more difficult: "You may fail to notice pertinent questions or issues because of the inability to step back from a situation and fully assess the circumstances" (Kitchin \& Tate, 2000, p. 29). Conducting insider interviews with students demands an attentive interviewer who is conscious about pursuing answers where the interviewee says "you know" and other implicit expressions. Otherwise, the interviewer may end up with empirical material that is of little or no use, because it is full of implicit remarks. On the other hand, the insider position also provides advantages such as easy access to the field and close knowledge of the context, culture and language (Adriansen \& Madsen, 2009).

The in-between position has been described by Chacko (2004) by the use of Entrikin (1991), as the position "between the objective pole of scientific theorising and the subjective pole of empathy and understanding" (Chacko, 2004, p. 54). As researchers interviewing our own students, we have experienced this in-between position ourselves and will add a third professional pole of interviewer curiosity. This curiosity often drives the questioning which can oscillate between the insider and outsider position. The distinction between being an insider and an outsider is not an easy one. Sikes and Potts (2008) have noticed that being an insider is common within educational research. They define an insider as somebody who is attached to or involved in the organisation or its social groups prior to commencing the study. By this definition, all teachers interviewing their own students are insiders. While we find this correct, it does not capture the dynamic aspect of the insider position. Therefore, we prefer to adopt Narayan's (1993) stance that we all belong to a number of communities simultaneously. Here also, the in-between position can be at play. To us, an insider is somebody who is considered an insider by the other members of a given community and/or who participates on par with the other members of that community. In this view, a teacher interviewing her own students can be both an insider and an outsider. The teacher is an insider in so far as she was present during teaching, but an outsider in the sense that she did not participate on par with the students. One might say that the interviewer and the interviewee were present at the same event but did not experience it from the same place all the time. This means that during an interview, the student can position the teacher in different ways from one minute to another. Likewise, the teacher can emphasise these different positions by asking questions in 


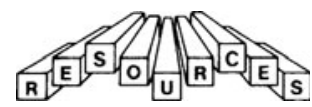

different ways, e.g. by drawing on the common knowledge from the classroom thereby emphasising the insider position or by asking from a distance to employ an outsider position.

Asking a colleague to interview one's students could be a way to avoid insider difficulties. We have tried interviewing a colleague's students about their approaches to learning GIS (both individual and focus-group interviews). Even though we were not insiders in Sikes' and Pott's (2008) understanding, it turned out we were insiders in relation to the subject matter. The students knew that we knew GIS and thereby it became difficult to ask outsider questions (reported in Madsen \& Nielsen, 2013; Madsen \& Rump, 2012). Being an insider both in relation to the subject matter and to the interviewees can be labelled "double insider". We have discussed the challenges this poses in Adriansen and Madsen (2009).

Interviews with students make power relations very present, but this is also the case in the opposite situation, i.e. when students interview researchers as seen - but not discussed - in Dwyer (2001). Student interviews of researchers may also be useful for developing a reflective practice, yet it is beyond the scope of the present paper. The power that a teacher can exercise over a student can inform the content of the interview. It goes without saying that the teacher has to think carefully about which questions to ask and how they should be asked. But the teacher should also consider her analytical power. Rose (1997) explains that the researcher holds a privileged position by deciding who is a relevant interviewee, by formulating the questions asked and when they are asked, by directing the flow of the discourse and by having the final power of interpretation. This is the analytical power of the researcher and it should not be neglected. Rose further links the analytical power of the researcher to the issue of distance. Even though the teacher and the students may be situated in the same landscape of power, there is still a distance between them because of the analytical power of the teacher. However, the students also have power in the sense that they hold the knowledge that the teacher wants. These power relations raise ethical questions some of which we will address in the next section.

\section{Ethical issues when interviewing one's students}

Researchers are required to consider ethical implications of their research (e.g. American Sociological Association, 2008). However, when interviewing one's own students, additional ethical issues are raised, e.g. regarding confidentiality and anonymity. When using interviews for becoming a reflective practitioner, confidentiality and anonymity only becomes a problem when the information from the interviews is shared with other people. In regard to using the interviews for analysing and publishing one's reflection on teaching practice, the usual aspects of confidentiality and anonymity in research apply. In the context of conducting student interviews in general, we want to point to three issues: The selection of interviewees, the interview location and the timing of the interview. These issues may seem banal, but in our experience it is important to reflect on them especially when interviewing one's own students.

The selection of interviewees: Besides being able to justify research design, the selection of students for interviews should be wise in regard to the signals it sends to students. Are the "clever" ones chosen, the "difficult" ones or those who seemed reflective in terms of pedagogy? While qualitative research design allows us to select critical cases or maximum variation (Flyvbjerg, 2006), doing so may send unfortunate signals to students. In one study, we asked the students to sign up themselves, thereby we did not have control over the selection. It worked well for reflection-on-action and we avoided 


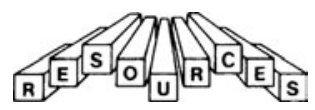

unethical signalling, but we did not have the best research design (Adriansen \& Madsen, 2013).

The interview location: As geographers we know that space matters, and this is also the case when interviewing (Elwood \& Martin, 2000; Sin, 2003). Different interview locations have different benefits and drawbacks for interviewing students. The benefits of interviewing at the location where teaching took place are as follows: the discussed activities can be placed in relation to each other, and the materials used during teaching may be present. The drawback is that power relations may be more difficult to overcome. Likewise, interviewing outside the classroom or even outside campus has its advantages and disadvantages. On the positive side: the explicit power relations can be diminished, especially off campus. However, both the power relations and ethical issues are still at stake. On the negative side: it may be awkward for the student and the teacher to meet off campus, e.g. in a cafe. If choosing a location on campus for interviewing, it is important to choose a location that does not resemble an exam situation.

The timing of the interview: By timing, we refer to scheduling of other activities one may have with the students; primarily timing in relation to exams. Just like the location should not resemble an exam, we would usually not recommend interviews prior to examining a student because the student may want to please the teacher and the answers therefore reflect the students' idea of a "good" answer instead of her perception of teaching and learning. Nevertheless, if the latter bias can be overcome, valuable information can be obtained by interviewing students before, during and after a course. We have made individual interviews with students about their learning process during a course on GIS in planning and management (Madsen, Christiansen, \& Rump, 2014). This study showed to us that interviewing the same students twice during the course provided valuable information on how the students' perceptions of the assignments and learning activities continuously were incorporated in the students' sense making of the course. A longitudinal setup with interviews during the course prior to the exam is necessary for constructing this type of reflection on students' learning processes.

Generally, we find that the unequal power relations make interviews with students more delicate than many other types of interviews. However, there are ways to level the analytical power of the teacher as discussed in the next section.

\section{The creation of visual co-constructions: a means to interview one's students}

In our experience, visual co-constructions can be used for balancing power relations. We focus on different ways of writing and drawing an interview (here called "pen and paper" interviews), but many of our considerations here can be translated to situations where other materials are used for creating visual co-constructions. The basic ingredients in a "pen and paper" interview are a large piece of paper and a number of coloured pens. The interview may be recorded (and transcribed); it depends on the type of analysis intended and on how the use of a recorder may affect the interviewee. Before we go into further detail with the pen and paper interview, we need to understand how visual coconstructions can affect power relations.

\subsection{Visual co-construction: a way of balancing power relations}

The benefit of using pens and (large pieces of) paper is that the student can participate in writing and drawing. After the teacher has explained the purpose of the interview and the process, she can encourage the student to take part in writing and drawing on the paper. 


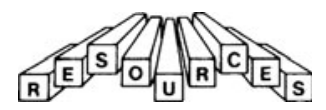

Kvale (1996) has explained that qualitative interviews are co-constructed. When the interviewer and the interviewee both participate in writing, the co-construction becomes physically explicit - a visual co-construction, as seen in Figure 1.

The paper serves as a "collective memory" where the content of the interview can be seen both by the interviewer and the interviewee. It is easy for both parties to return to an issue already discussed and this can be linked with other events along the way. Whether the interviewee is participating in writing or not, she is usually engaged in following how the interview unfolds on the paper. This is quite different from a "conventional" interview. The visualisation on the paper affects how the interview is conducted. While some researchers (e.g. Goodson \& Sikes, 2001) recommend that the interviewer keeps eye contact with the interviewee, we find that it is culturally specific what constitutes appropriate eye contact. While eye contact can create an intimate atmosphere, it can also be intimidating. In our experience, it can be easier to talk about personal issues when there is no eye contact, but an atmosphere of presence - for instance because both the interviewee and the researcher are engaged in the same activity such as drawing. As an interviewer said after conducting a pen and paper interview: "The paper removes the focus from the slightly formal situation" (Adriansen, 2012, p. 50).

Furthermore, there are two important and intertwined points, which we consider benefits of visual co-constructions. These concern ownership and analytical power.

Ownership: In our experience, interviewees often take ownership of this type of interview. This was evident when the interviewee wanted a copy of paper afterwards something we have experienced more than once with pen and paper interviews but interviewees have never asked for our notes or the digital recording after a "conventional" interview. Hence, using the paper as a collective memory can make the interview a collective process allowing the interviewee to take ownership. She has the possibility to steer the interview in a certain direction, although it is still the interviewer who ultimately holds the analytical power and can decide which issues are relevant for the interview.

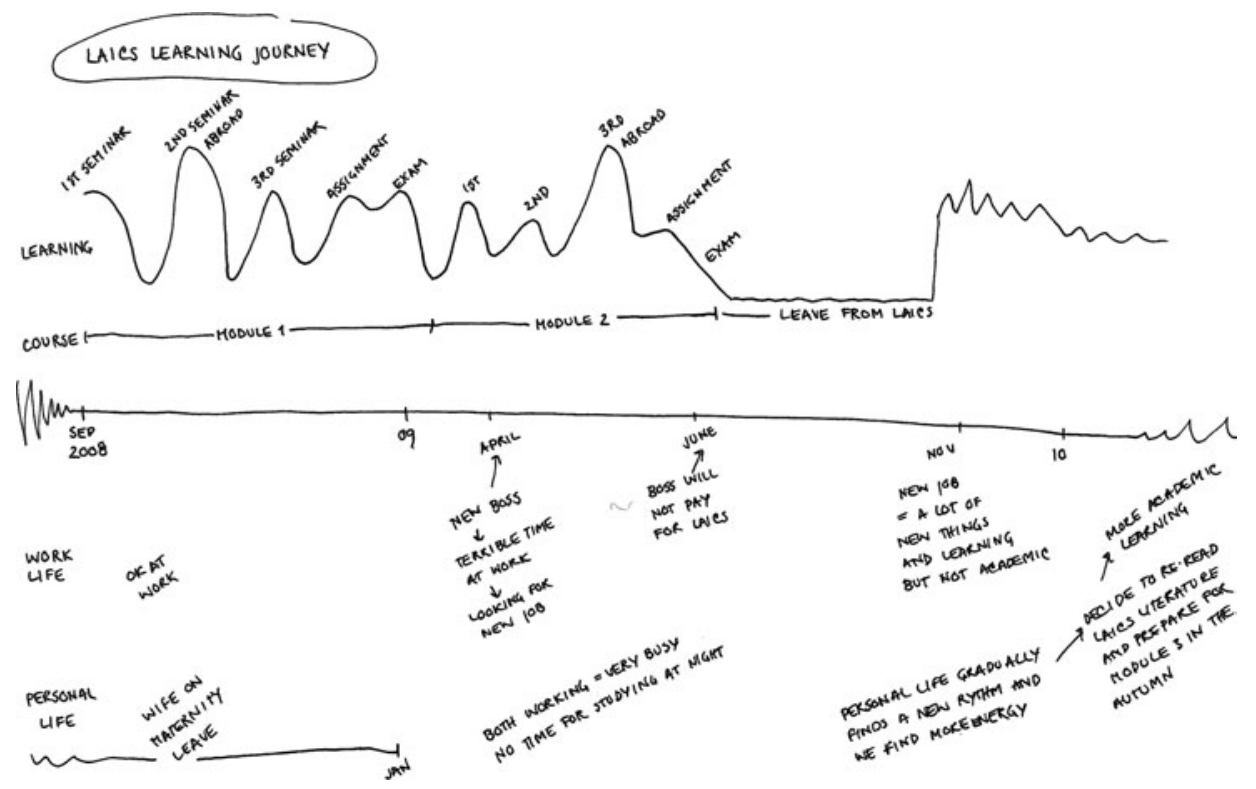

Figure 1. An example of a learning journey interview from the study of creativity and criticality. 


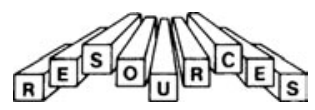

Analytical power: In "conventional" interviews, the interviewer holds the analytical power. It is the interviewer who decides that the interviewee is a relevant person to talk to; it is the interviewer who constructs the interview guide and it is the interviewer who asks the questions (Kvale, 1996). When conducting a "pen and paper" interview, it is still the interviewer who decides that the interviewee is a relevant person to talk to, the type of questions asked and the way the interview is conducted. So far, the analytical power is held by the interviewer. When the "pen and paper" interview starts, however, the situation is different from a "conventional" interview because the interviewee is invited to participate in "constructing the interview". In this way, the analytical power is shared, although not equally, in the interview situation. The creation of visual co-constructions allows the interviewer and the interviewee to be situated closer in the landscape of power - to use the vocabulary of Rose (1997). However, when the interview ends, it is not different from other qualitative interviews; here the analytical power belongs to the researcher solely.

\subsection{Using time as an organising principle: timeline interviews}

We have analysed the use of timelines interviews elsewhere (Adriansen, 2012), here a few words on the technique suffices. The backbone of the method is the drawing of a timeline in the middle of the paper in the "pen and paper" interview. Ordering of events can be guiding the interview. An important issue is when the timeline should begin and end.

In an educational setting, it could begin with the interviewee's first university experience, enrolment in a specific course or a significant event prior to university important for the interviewee's choice of education. Likewise, the timeline could also continue into the future to capture how the student sees her future use of the competences she has gained. The paper is a physical layout which permits different lines representing different perspectives; these may be the "core" of the story, e.g. the course/degree programme/student life in the middle and family/outside towards the edges. Thereby, there is an emphasis on unfolding the context and its ascribed meaning for the student's choices and experiences. Usually, the interviewee begins with the most important events, which are noted on one side of the timeline and gradually "outside" events that have affected the events may come up as the story unfolds and are noted on the other side of the line. When trying to place events in order, the interviewee sometimes realises that these events took place in a different order from what she initially remembered; when conducting focus group interviews, disagreements among the group are also laid out very clearly. This may mean that they re-negotiate their story. In this way, the paper and the drawings along the timeline become important visual tools for seeing how the story is constructed.

\subsection{Using time and space as organising principles: learning journey interviews}

The timeline interview uses time as an organising principle. Likewise, space or location can be used in a "pen and paper" interview as an organising principle. Inspiration can be found within geographical research (e.g. Oldrup \& Carstensen, 2012; Tani \& Surma-aho, 2012).

A learning journey interview is a combination of the two methods mentions above. A learning journey is the learning process experienced during time and space. In principle, the journey can be any course or learning process at university or elsewhere. The benefits of using interviews of students' learning journeys are that it becomes possible to link 


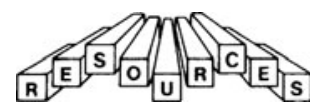

learning activities to other activities in space and time. Example 2 below, together with Figure 1, provides a description of how we have used individual learning journey interviewes for our reflection-on-action.

Example 2: The chapter "How criticality affects students' creativity" (Adriansen, 2010) is an example of our own reflective practice. Higher education is met with increasing demand for providing students with creative and innovative competencies. How can these competencies be reconciled with critical thinking which is the hall mark of Academia? Does teaching the subject matters creativity and innovation mean that we have to be creative and innovative in our way of teaching? If yes, how do we practice what we preach? These questions were answered during a reflective process including student interviews. We also read relevant literature which was outside our field of research but provided valuable input for reflection. The process ended with a book chapter based on student interviews and reflection. In this way, the time spent on reflection provided useful output "for the system" as well as reflection-on-action.

The learning journey approach gave rise to detailed accounts of when the students felt motivated and experienced high learning and vice versa. One of the interviewees explained how she had experienced the first seminar as unstructured and very confusing, even frustrating, leaving the seminar with more questions than answers:

"I had a feeling of having wasted three days (Adriansen, 2010, p. 73)".

But already when preparing the first assignment, she became a little more positive:

"I could feel that I had some new thoughts, was thinking in a new way (Adriansen, 2010, p. 73)".

And in hindsight, she could see how the first seminar had made sense, how it had prepared her for the journey.

The drawings of the learning journeys (Figure 1) showed how the location of the seminar (whether in Denmark or abroad) also affected the intensity of their learning. This information was invaluable for understanding our role as teachers and for reflecting on the importance of location as well as the coherence of the degree programme.

\section{Discussion and concluding remarks}

In this paper, we have shown how to address challenges involved in conducting qualitative interviews with one's own students for the purpose of becoming reflective geographers. Being an insider in relation to one's interviewees presents difficulties and advantages as well as ethical dilemmas. All this calls for reflection. We have shown how reflection on the subtle nuances of the interview setting and experiences can be used. This paper may be seen as a "meta-reflection" on reflection-on-action, a reflection on how to reflect on our actions as geography teachers. The reason why we encourage student interviews as a tool for reflection-on-action is that qualitative interviews can provide us with in-depth understanding of a student's life-world, their meaningmaking and ways of learning. These are issues we find important for any teaching professional wanting to develop her reflection on her teaching practice.

We have argued that we may find the resources for developing a reflective practice by using our reflections as input for research. But one question remains: why should our students spend their valuable time on being interviewed? The answer can be found in Kvale's (1996) notion of the interview as a co-construction where the interviewee is affected and also has learned something through the interview. Hence, participating in such an interview would hopefully lead to reflection-on-action for both the interviewer and the interviewee. Some scholars have argued that higher degree students should develop a reflective practice - usually through journal writing (Boud, 2001; Cunliffe, 2004; Morrison, 1996). We would argued that a reflective practice may not (only) be developed in solitude; it can be a collective endeavour developed through qualitative interviews. 


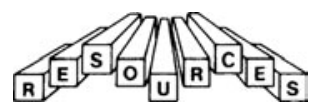

While we find qualitative interviews beneficial for developing a reflective practice, teachers should be prepared for the challenges and ambiguities involved when interviewing one's own students. As an insider interviewer, one becomes an integral part of the process. We concur with Wilson (1997) that if researchers are not prepared for that, then they have better choose another method. ${ }^{2}$

Based on our findings, we have extracted the following recommendations for teachers who want to interview their students for reflection-on-action. The recommendations are also applicable when researchers want to interview their students for other purposes such as course evaluation, getting feedback and ideas for course development:

- Pay attention to positionality during the interview process - also before and after, i.e. when recruiting interviewees and when reporting back to them. There are three important (sets) of positions - the teacher/researcher-student position, the insider/ outsider position and the in-between position.

- The teacher/researcher-student position has to do with power relations and one's respective identities. One's position as a researcher/teacher and the student's as learner can be at stake in the process. Being explicit about one's role and their roles may help both the students and the researcher/teacher to reflect upon them. As a teacher, one should be aware of and pay attention to the ethics involved. This can be done by carefully selecting interviewees, and mindfully choosing a time and place for the interview.

- Using visual co-construction for interviewing may affect ownership and analytical power in a positive manner.

- The insider position provides both benefits and drawbacks: Make the most of the benefits (easy access to the field and close knowledge of the context), and be aware of how to handle the drawbacks e.g. pursue implicit answers and presupposed shared understandings.

\section{Notes}

1. Both the teacher position and the researcher position are present and at stake when interviewing one's own students. In the following, we use the word teacher or researcher depending on which position is most important in the context.

2. Wilson made the remark in the context of focus group interviews in educational research, but we find it equally valid for the arguments made here.

\section{References}

Adriansen, H. K. (2010). How criticality affects students' creativity. In C. Nygaard \& C. Holtham (Eds.), Teaching creativity-creativity in teaching (pp. 65-84). Faringdon, Oxon: Libri Publishing.

Adriansen, H. K. (2012). Timeline interviews: A tool for conducting life history research. Qualitative Studies, 3, 40-55.

Adriansen, H. K., \& Knudsen, H. (2013). Two ways to support reflexivity: Teaching managers to fulfil an undefined role 'A problem cannot be solved at the same level of thinking that created it'. Teaching Public Administration, 31, 108-123.

Adriansen, H. K., \& Madsen, L. M. (2009). Studying the making of geographical knowledge: The implications of insider interviews. Norsk Geografisk Tidsskrift-Norwegian Journal of Geography, 63, 145-153.

Adriansen, H. K., \& Madsen, L. M. (2013). Facilitation: A novel way to improve students' wellbeing. Innovative Higher Education, 38, 295-308.

American Sociological Association. (2008). Code of ethics and policies and procedures of the ASA committee on professional ethics. Washington, DC: The Association. 


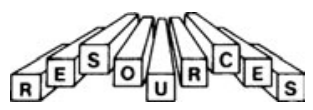

Boud, D. (2001). Using journal writing to enhance reflective practice. New Directions for Adult and Continuing Education, 2001, 9-18.

Chacko, E. (2004). Positionality and praxis: Fieldwork experiences in rural India. Singapore Journal of Tropical Geography, 25, 51-63.

Cunliffe, A. L. (2004). On becoming a critically reflexive practitioner. Journal of Management Education, 28, 407-426.

DeVerteuil, G. (2004). Systematic inquiry into barriers to researcher access: Evidence from a homeless shelter. The Professional Geographer, 56, 372-380.

Dewey, J. (1933). How we think: A restatement of the relation of reflective thinking to the educational process. Lexington, MA: Heath.

Dwyer, C. (2001). Linking research and teaching: A staff-student interview project. Journal of Geography in Higher Education, 25, 357-366.

Elwood, S. A., \& Martin, D. G. (2000). "Placing" interviews: Location and scales of power in qualitative research. The Professional Geographer, 52, 649-657.

England, K. V. L. (1994). Getting personal: Reflexivity, positionality, and feminist research. The Professional Geographer, 46, 80-89.

Entrikin, J. N. (1991). The betweenness of place: Towards a geography of modernity. Baltimore, MD: Johns Hopkins University Press.

Flyvbjerg, B. (2006). Five misunderstandings about case-study research. Qualitative Inquiry, 12, $219-245$.

Goodson, I., \& Sikes, P. J. (2001). Life history research in educational settings: Learning from lives. Milton Keynes: Open University Press.

Kent, A. (2000). Reflective practice in geography teaching. London: Sage.

Kitchin, R., \& Tate, N. J. (2000). Conducting research in human geography: Theory, methodology and practice. London: Prentice Hall.

Kvale, S. (1996). Interviews: An introduction to qualitative research interviewing. Thousand Oaks, CA: Sage.

Larner, W. (1995). Theorising 'difference' in Aotearoa/New Zealand. Gender, Place and Culture: A Journal of Feminist Geography, 2, 177-190.

Madsen, L. M., \& Adriansen, H. K. (2006). Knowledge constructions in research communities: The example of agri-rural researchers in Denmark. Journal of Rural Studies, 22, 456-468. doi:10.1016/j.jrurstud.2006.02.001

Madsen, L. M., Christiansen, F. V., \& Rump, C. (2014). Students individual engagement in GIS. Journal of Geography in Higher Education, 38, 251-265.

Madsen, L. M., \& Nielsen, T. T. (2013). Learning to do geography? University students posing questions in GIS laboratory exercises. Norsk Geografisk Tidsskrift-Norwegian Journal of Geography, 67, 157-161.

Madsen, L. M., \& Rump, C. (2012). Considerations of how to study learning processes when students use GIS as an instrument for developing spatial thinking skills. Journal of Geography in Higher Education, 36, 97-116. doi:10.1080/03098265.2011.576336

Madsen, L. M., \& Winslow, C. (2009). Relations between teaching and research in physical geography and mathematics at research-intensive universities. International Journal of Science and Mathematics Education, 7, 741-763. doi:10.1007/s10763-008-9134-y

McCleery, A. (2004). So many Glasgows: From 'personality of place' to 'positionality in space and time'. The Scottish Geographical Magazine, 120, 3-18.

Morrison, K. (1996). Developing reflective practice in higher degree students through a learning journal. Studies in Higher Education, 21, 317-332.

Naidoo, R. (2008). The competitive state and the mobilised market: Higher education policy reform in the United Kingdom (1980-2007). Critique Internationale, 39, 47-65.

Narayan, K. (1993). How native is a "native" anthropologist? American Anthropologist, 95, $671-686$.

Oldrup, H. H., \& Carstensen, T. A. (2012). Producing geographical knowledge through visual methods. Geografiska Annaler: Series B, Human Geography, 94, 223-237.

Piaget, J., Ackermann, E., \& Berthoud-Papandropoulou, I. (1977). Recherches sur l'abstraction réfléchissante. Paris: Presses Universitaires de France.

Rose, G. (1997). Situating knowledges: Positionality, reflexivities and other tactics. Progress in Human Geography, 21, 305-320. 


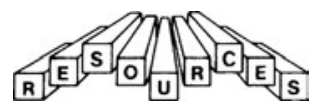

Schön, D. A. (1983). The reflective practitioner: How professionals think in action. New York: Basic Books.

Sikes, P., \& Potts, A. (2008). Researching education from the inside: Investigations from within. Oxon: Routledge.

Sin, C. H. (2003). Interviewing in 'place': The socio-spatial construction of interview data. Area, 35, $305-312$.

Tani, S., \& Surma-aho, O. (2012). Young people and the hidden meanings of the everyday: Time-space path as a methodological opportunity. International Research in Geographical and Environmental Education, 21, 187-203.

Wilson, V. (1997). Focus groups: A useful qualitative method for educational research? British Educational Research Journal, 23, 209-224. 